\title{
STUDI IDENTIFIKASI KERUSAKAN LERENG KAMPUS FAKULTAS ILMU ADMINISTRASI UNIVERSITAS LANCANG KUNING
}

\author{
Fitridawati Soehardi ${ }^{1}$, Marta Dinata ${ }^{2}$, Lusi Dwi Putri*3 \\ ${ }^{13}$ Program Studi Teknik Sipil, Fakultas Teknik, Universitas Lancang Kuning \\ ${ }^{2}$ Program Studi Pendidikan Biologi, Fakultas FKIP Universitas Lancang Kuning \\ Jalan Yos Sudarso Km.8 Rumbai Pekanbaru \\ *Corresponding authors: Lusidwiputri@unilak.ac.id
}

Received: 01 September 2019, Accepted: 11 Oktober 2019

DOI: $10.31849 /$ siklus.v5i2.3208

\begin{abstract}
Abstrak
Penelitian ini bertujuan untuk mengidentifikasi permasalahan kerusakan pada lereng kampus Fakultas Ilmu Administrasi Universitas Lancang Kuning. Pelaksanaan penelitian ini menggunakan Metode pengamatan langsung dilapangan dan studi literatur. Hasil data yang diperoleh di sajikan dalam bentuk gambar kerusakan pada lereng kampus Fakultas Ilmu Administrasi Universitas lancang Kuning. Kondisi lereng Menunjukkan tingkat Kerusakan yang cukup signifikan karena lereng masih dalam keadaan alami. Berdasarkan pengamatan dilapangan kelongsoran lereng pada Kampus Fakultas Ilmu Administrasi Universitas Lancang Kuning terjadi karena air hujan yang masuk kedalam pori-pori tanah sehingga mengakibatkan lunaknya tanah sehingga tanah mengalami kehilangan kapasitas dukungnya. Hal ini diperparah dengan penumpukan daun akasia yang menambah tingkat kelembaban pada tanah.
\end{abstract}

Kata kunci : Lereng, tanah longsor, dinding penahan tanah

\begin{abstract}
This study aims to identify the problem of the slopes damage of in Faculty of Administrative Sciences, Lancang Kuning University. The implementation of this research uses the method of direct observation in the field and study of literature. The results of the data obtained are presented in the form of damage imaging of slopes Faculty of Administrative Sciences, Lancang Kuning University. The condition of the Slope shows a significant of damage level due to the slope is still in a natural state. Based on field observations, slope's failure, in Faculty of Administrative Sciences Lancang Kuning University is due to rainwater that enters the soil pores, resulting in soft soil so that the soil loses its carrying capacity. This is compounded by the accumulation of acacia leaves which adds moisture of the soil.
\end{abstract}

Keywords : Slope, slope failure, retaining wall of the soil 


\section{A. PENDAHULUAN}

Lingkungan kampus Universitas Lancang Kuning memiliki luas lahan lebih kurang 77 Hektar dan memiliki perbedaan kontur tanah yang berbeda. Pada beberapa lokasi kontur tanah cukup curam (berlereng) diantaranya terdapat pada beberapa bangunan yaitu. Akses gerbang selatan.(Haris, Lubis, \& Winayati, 2018), Fakultas Ekonomi (Zainuri, Yanti, \& Megasari, 2016), dan Kampus Ilmu Asministrasi, Fakultas Teknik.

Berdasarkan kondisi tersebut perlu adanya penanganan menggunakan dinding penahan tanah untuk menjaga kesetabilan lereng tanah agar pondasi bangunan tetap dapat stabil menyangga tanah dalam memikul struktur diatasnya. Kampus Fakultas Ilmu Pemerintahan Universitas Lancang Kuning dibangun pada daerah yang mempunyai kontur tanah yang berbukit dengan ketinggian lereng antara 5-6 meter dengan panjang \pm 80 meter, dan berbatasan langsung dengan Jalan Patria Sari Kelurahan Rumbai Pekanbaru. Curah Hujan Yang Tinggi pada bulan November 2018 lereng tersebut mengalami kelongsoran, hal ini dapat meresahkan dan membahayakan bagi pengguna jalan yang melintasi areal tersebut. Penanganan kelongsoran telah dilakukan oleh Pihak berwenang dengan melakukan perkuatan menggunakan cerocok kayu di sepanjang areal longsoran. Namun hal ini belum maksimal karena jika curah hujan tinggi maka kemungkinan terjadinya longsoran akan terjadi kembali. Oleh karena itu penulis melakukan penelitian tentang identifikasi kerusakan lereng Kampus Fakultas Ilmu Administrasi Universitas Lancang kuning dari hasil penelitian ini diharapkan dapat memberi masukkan terhadap penanganan tanah longsor yang terjadi.

\section{B. TINJAUAN PUSTAKA}

\section{Pengertian Tanah Longsoran}

Tanah longsor (landslides) merupakah suatu peristiwa yang biasa terjadi pada kondisi lereng-lereng alam (natural slopes) maupun pada lereng buatan manusia (man made slopes). Pada akhir musim penghujan Peristiwa longsor merupakan bencana alam yang mempunyai frekuensi terjadinya sangat tinggi sehingga peristiwa longsoran sering sekali dikaitkan dengan frekuensi curah hujan yang tinggi (Fadhilah \& Sudarno, 2017).

Longsoran Tanah Merupakan proses bergeraknya massa tanah (soil mass movement) pada lereng-lereng alam mau buatan yang didominasi oleh pergerakan yang terjadi pada massa tanah melalui suatu bidang pada lereng, baik berupa bidang miring ataupun lengkung. Longsoran dapat diakibatkan oleh gangguan secara alamiah yang dapat disebabkan tidak stabilnya tanah atau batuan penyusun lereng, baik yang bersifat alamiah maupun non alamiah.

Tanda - tanda awal dari Tanah Longsor adalah adanya retakan pada bagian atas lereng yang kondisinya relatif tegak lurus arah gerakan tanah. Apabila retakan ini bila tidak segera ditutup,maka ketika hujan retakan akan terisi oleh air yang mengakibatkan melunakkan tanah dan menambah gaya horisontal yang memicu tanah longsoran. Jika ingin memahami longsorang maka kita harus mengetahui bagian dari geomerti longsoran tersebut, hal ini sangat diperlukan dalam upaya pencegahan dan Penanganan bahaya longsoran. 


\section{Faktor Penyebab Tanah Longsor}

Tanah Longsor pada umumnya dipengaruhi oleh banyak faktor seperti kondisi tanah, kondisi geometri lokasi, pola drainase, kondisi vegetasi tumbuhan dan kondisi geologi lokal(Hardiyatmo, 2007) yang dapat mempengaruhi secara bersamaan.

Secara garis besar penyebab utama terjadinya tanah longsor dibagi menjadi dua yaitu:

\section{Faktor Penyebab Alami}

Penyebab terjadinya tanah longsor akibat proses tanah longsor yang disebabkan oleh faktor dari alam .

a. Kuat geser turun dan Tekanan overburden berkurang sehingga tanah dan batuan mengembang, hal ini akibat penggalian kaki lereng si sepanjang galian yang mengakibatkan kelongsoran.

b. Peningkatan posisi muka air secara cepat (rapid drawdown) pada sungai, bendungan, dan lain-lain.

c. Beban bangunan dan beban dinamis yang disebabkan tiupan angin pada pohon dan lain-lain mengakibatkan bertambanhnya beban pada lereng

d. Air terutama air hujan mengakibat tekanan lateral bertambah.

e. Penggalian atau pemotongan kaki lereng.

f. Penggalian yang mempertajam kemiringan lereng.

g. Penggalian lerang untuk jalan raya, jalan rel dan pembangunan di atas lereng sebagai salah satu pemicu terjadinya kelongsoran.

h. Penurunan tahanan geser tanah pembentuk lereng dapat mengakibatkan tekanan rembesan, kenaikan kadar air, kenaikan tekanan air pori, yang dapat disebabkan oleh genangan air di dalam tanah khususnya lereng yang mengandung lempung dan mudah mengembang.

i. liquefaction pada pasir atau lanau longgar yang jenuh air disebabkan oleh Getaran atau gempa bumi (Achmad, 2010).

2. Faktor Penyebab Oleh Ulah manusia Tanah Longsor Yang dipengaruhi oleh aktifitas manusia baik secara langsung maupun tidak langsur yang dapat berdampak terhadap kerusakan alam. Sehingga mengakibatkan perubahan secara drastic terhadap material, struktur, tanah maupun batuan. Beberapa contoh tanah longsor yang diakibatkan ulah manusia antara lain

a. Lereng bekas galian badan jalan merupakan lokasi yang rawan longsor. Kaki lereng di sepanjang galian sangat mudah tergerus air sehingga menghilangkan dukungan tanah terhadap longsoran.

b. Lereng yang sangat terjal mempunyai kemiringan lebih dari 400 dan mempunyai banyak batuan lepas sangat berbahaya, terutama bagi keselamatan pengguna dan pengendara kendaraan yang melitas di areal tersebut karena rentan terjadi longsor.

c. Sistem Drainase yang tidak berfungsi dengan baik akan memicu aliran air yang tidak teratur dan mengurangi kestabilan lereng.

d. Mengalihkan aliran air permukaan atau air tanah ke 
lokasi yang rawan potensi longsor.

e. Kegiatan pertambangan serta penggalian material Tanah Maupun batuan

f. Pengaruh dari aktivitas lalulintas kendaraan yang padat, peledak dan lain-lain yang mengakibat kan meninggkatnya getaran pada struktur tanah

g. Penebangan pohon dan mengakibatkan berubahnya vegetasi tumbuhan yang mampu menahan runoff air permukaan.

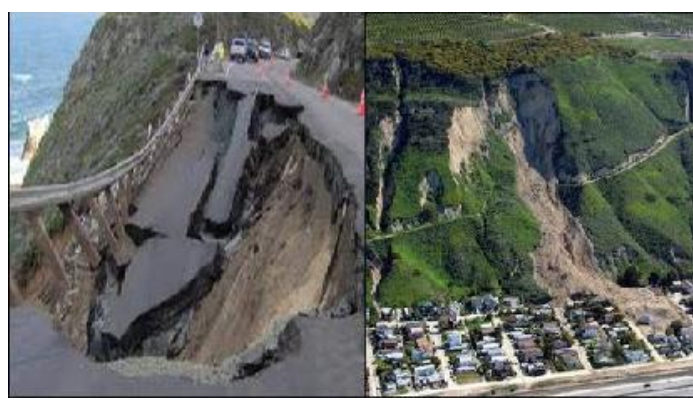

Gambar 1. Bencana Tanah Longsor akibat ulah manusia

\section{Prinsip Kestabilan Lereng}

Gaya-gaya yang bekerja melongsorkan (driving forces) tanah atau batuan dan gaya-gaya yang berusaha mempertahankan (resisting forces) tanah atau batuan itu tetap pada posisinya mempengaruhi nilai kestabilan pada lereng ditentukan oleh. (Achmad, 2010) nilai kohesi (c) dan sudut gesek dalam antara partikel-partikel penyusun tanah atau batuan $(\varphi)$ mempengaruhi besarnya kuat geser tanah atau batuan (Lestari, 2017).

Kestabilan suatu lereng yaitu perbandingan antara gaya-gaya penahan logsor dan gaya-gaya penyebab longsoran, atau dapat dirumuskan sebagai berikut :

$$
\mathrm{SF}=\frac{\text { Gaya Penahan Longsor }}{\text { Gaya Penyebab Longsor }}
$$

FK merupakan faktor keamanan (Factor of Safety) yang menggambarkan kondisi suatu lereng. Lereng dalam kondisi stabil, jika FK > 1; lereng dalam kondisi kritis, jika FK = 1; lereng dalam kondisi tidak stabil atau telah longsor, jika FK < 1(Achmad, 2010)

\section{Dinding Penahan Tanah}

Dinding penahan tanah merupakan konstruksi yang berfungsi menahan tanah agar tidak terjadi longsor. Konstruksi ini digunakan untuk suatu tebing yang agak curam / tegak dimana kemantapannya tidak stabil sehingga memerlukan dinding penahan agar tidak terjadi longsor. Dinding penahan tanah juga digunakan bila suatu jalan dibangun berbatasan dengan sungai, danau (Gholo, 2014).

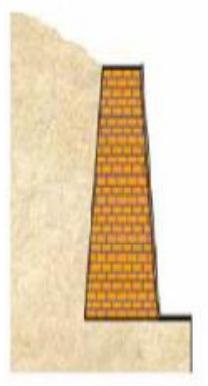

(a)

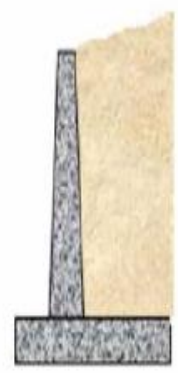

(b)

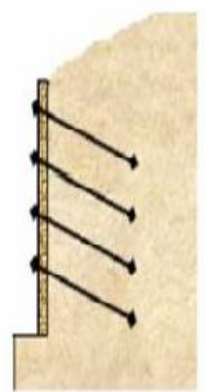

(c)
Gambar 2. Dinding Penahan Tanah a) Gravity, b) Cantilever, c) Dinding dengan Jangkar.

Dinding penahan tanah yang digunakan harus stabil terhadap pergeseran, penggulingan, dan keruntuhan kapasitas daya dukung tanah. Nilai faktor aman terhadap penggulingan $>1,5$, terhadap pergeseran $>1,5$, dan terhadap keruntuhan kapasitas daya dukung $>3$. 


\section{METODE PENELITIAN}

Penelitian ini dilakukan pada areal kampus Ilmu Administrasi Universitas Lancang Kuning. Ada 2 Metode penelitian yang dilakukan yaitu pertama, pengamatan langsung dilapangan melalui survey tentang kondisi keadaan lereng dan vegetasi tumbuhan. Kedua, studi literature terhadap hasil penelitianpenelitian terdahulu tentang penanganan longsor dan dinding penahan tanah serta data-data pendukung lainnya. Data yang diperoleh dari hasil survey lapangan

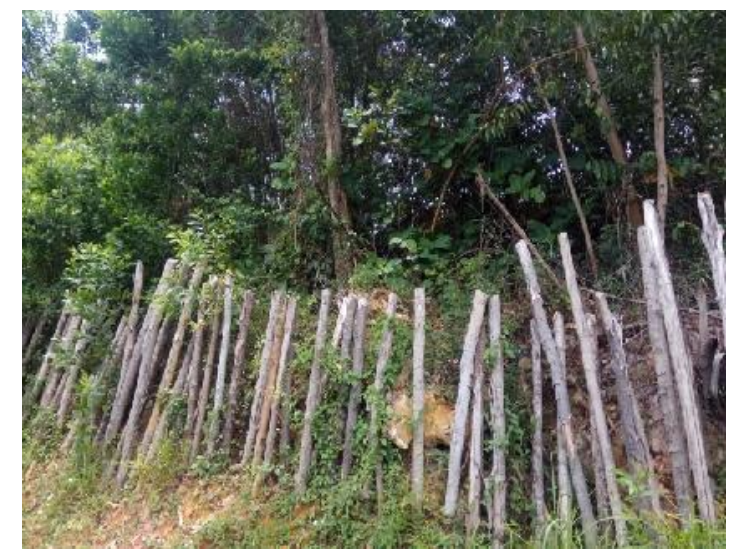

kemudian dianalisa sehingga dapat mengidentifikasi kerusakan lereng dan penanganan yang sesuai berdasarkan kajian-kajian penelitian sebelumnya, dan ditampilkan dalam bentuk gambar kondisi lereng dan tabel pembahasan.

\section{HASIL DAN PEMBAHASAN}

\section{Kondisi Lereng}

Hasil pengamatan dilapangan diketahui bahwa kondisi lereng mengalami kelongsoran dibeberapa titik seperti yang dapat dilihat pada gambar 3

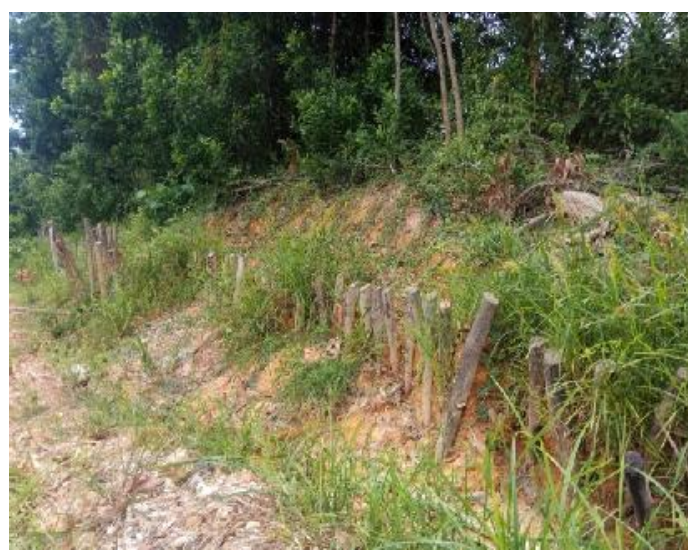

Gambar 3. Kondisi alami lereng setelah longsor dan diberi perkuatan cerocok kayu

Salah satu faktor penyebab terjadinya longsoran pada kampus Fakultas Ilmu administrasi Universitas Lancang Kuning adalah akibat meningkatnya kandungan air dalam tanah sehingga tanah yang ada kehilangan daya ikat dan cendrung lembab. Hal ini dapat disebabkan oleh meningkatnya intensitas curah hujan yan relatif tinggi dengan durasi yang lama yang menyebabkan perubahan atau peningkatan kandungan air dalam tanah. Peningkatan curah hujan menjadi pemicu terjadinya longsor, hal ini merubah kondisi tanah yang sebelumnya kondisi tidak jenuh air (unsaturated) menjadi jenuh air (saturated), perubahan ini berdampak pada parameter kuat geser tanah terutama kohesi (c) antar butiran akan berkurang. Energi Kinetik yang dimiliki oleh air hujan yang turun kepermukaan tanah dapat menghancurkan butiran-butiran tanah sehingga mengakibatkan bagian-bagian tanah tterhempas, hanyut dan hilang oleh proses bergeraknya aliran air hujan. Kondisi inilah disebut juga dengan erosi.(Fitridawai Soehardi \& Dinata, 2018).

Keruntuhan lereng dipicu terjadinya kembang susut tanah yang terjadi akibat perubahan kandungan air. Apabila perubahan volume air pada tanah lereng terjadi maka akan menimbulkan pergerakan tanah sehingga memungkinkan terjadinya longsoran yang dapat mengakibatkan kerusakan yang cukup berarti. (Karnawati, 2005). 
Air hujan yang berinfiltrasi ke dalam tanah yang lolos air (permeable) akan berakumulasi pada kaki lereng dan menyebabkan muka air tanah naik, sehingga memperbesar tekanan hidrostatis pada lereng tersebut. Infiltrasi air ke dalam tanah, menghilangkan tekanan air pori negatif dan menaikan tekanan air pori positif yang mengurangi kuat geser tanah. Air hujan juga dapat menyebabkan hilangnya ikatan tanah (soil suction)(Achmad, 2010).

Vegetasi tumbuhan juga dipengaruhi oleh curah hujan yang tinggi sehingga mengakibatkan kelembaban yang tinggi. Hal ini dapat dilihat dari penumpukan serasah daun akasia yang tebal yang menyebabkan dinding tanah penahan pinggir menjadi lunak karena lembab dan berpotensi menjadi longsor.(Dinata, Fitridawati, \& Putri, 2019)

\section{Upaya Penanganan Longsor}

Penanganan lereng kampus Fakultas Ilmu Administrasi Universitas Lancang Kuning telah dilakukan menggunakan cerocok kayu namun hal ini masih bersifat sementara dan perlu ada penanganan yang serius agar tidak mengakibatkan kerusakan yang lebih parah lagi. Berdasarkan penyebabpenyebab yang diuraikan diatas, maka masalah air menjadi penyebab utama terjadinya longsoran. Langkah-langkah selanjutnya yang dapat dilakukan guna mencegah terajadinya longsor antara lain:

1. Perubahan jalur Air Permukaan

Mengalihkan aliran air permukaan pada areal longsor dengan cara menggali parit di sekitar puncak lereng.

\section{Drainase Permukaan}

Upaya untuk mereduksi genangan air dan mengontol aliran air permukaan pada daerah yang rawan terjadi kelongsoran dapat dilakukan dengan membangun drainse permukaan contohnya parit terbuka yang berfungsi untuk memindahkan aliran air yang masuk kedalam daerah yang tidak stabil. Namun perlu diperhatikan dalam pembuatan draenasi karena perlu ke hati-hatian Karen kemungkinan dapat memperparah kondisi daerah lonsor tersebut.

\section{Shotcrete}

Shotcrete atau penyemenan adalah upaya untuk perlindungan lereng dari bahaya infiltrasi air hujan yang akan masuk ke dalam tanah. Bahan yang dipergunakan adalah campuran beton, namun dengan persyaratan agregatnya tidak boleh lebih dari $3 / 8$ inci, dan perlu diperhatikan diperhatikan adalah posisi memasang lubang-lubang drainase (pipa) di dalam shotcrete karena akan mempengaruhi aliran air yang keluar dan ketahanan dari shotcrete tersebut.

Pada penelitian ini dirangkum dari beberapa penelitian sebelumnya tentang penanganan kelongsoran menggunakan dinding penahan tanah. Berdasarkan hasil riset peneliti-peneliti sebelumnya diperoleh informasi keuntungan dan kerugian penggunaan dinding penahan tanah sehingga dapat dipakai sebagai rekomendasi penanganan kelongsoran di Fakultas Ilmu Administrasi Universitas Lancang Kuning. Sehingga dapat diambil kesimpulan seperti diperlihatkan pada tabel 1 . 
Tabel 1. Perbandingan Berbagai Jenis Perkuatan untuk lereng

\begin{tabular}{|c|c|c|c|c|c|c|c|c|c|c|c|}
\hline \multirow[t]{2}{*}{$\begin{array}{c}\text { Jenis } \\
\text { Perkuatan }\end{array}$} & \multicolumn{2}{|c|}{ Kekuatan } & \multicolumn{2}{|c|}{ Daya Tahan } & \multicolumn{2}{|c|}{$\begin{array}{l}\text { Ketersediaan } \\
\text { Produk }\end{array}$} & \multicolumn{2}{|c|}{ Harga } & \multicolumn{2}{|c|}{ Fungsi } & \multirow[t]{2}{*}{ Referensi } \\
\hline & Tarik & Tekan & Awet & $\begin{array}{c}\text { Umur } \\
\text { Layanan }\end{array}$ & Mudah & Sulit & Murah & Mahal & $\begin{array}{l}\text { Draina } \\
\text {-se }\end{array}$ & $\begin{array}{c}\text { Perku } \\
\text { atan }\end{array}$ & \\
\hline Cerucuk Kayu & & $\sqrt{ } \sqrt{ }$ & $\sqrt{\sqrt{ }}$ & $\sqrt{\sqrt{ }}$ & $\sqrt{ }$ & $\sqrt{ }$ & & $\sqrt{\sqrt{ }}$ & & $\sqrt{\sqrt{ }}$ & $\begin{array}{c}\text { (Rusdians } \\
\text { yah, 2016) }\end{array}$ \\
\hline $\begin{array}{l}\text { Anyaman } \\
\text { Bambu }\end{array}$ & $\sqrt{\sqrt{ }}$ & $\sqrt{ }$ & $\sqrt{\sqrt{ }}$ & $\sqrt{\sqrt{ }}$ & $\sqrt{\sqrt{ }}$ & $\sqrt{ }$ & $\sqrt{\sqrt{ }}$ & & $\sqrt{\sqrt{ }}$ & $\sqrt{\sqrt{ }}$ & $\begin{array}{l}\text { (Adi, } \\
\text { 2016) }\end{array}$ \\
\hline $\begin{array}{l}\text { Karung } \\
\text { Goni }\end{array}$ & $\sqrt{ }$ & $\sqrt{ }$ & $\sqrt{ }$ & $\sqrt{ }$ & $\sqrt{\sqrt{ }}$ & & $\sqrt{\sqrt{ }}$ & & $\sqrt{ } \sqrt{ }$ & $\sqrt{ } \sqrt{ }$ & $\begin{array}{l}\text { (Murri, } \\
\text { Surjandar, } \\
\text { \& As;ad, } \\
\text { 2014) }\end{array}$ \\
\hline $\begin{array}{l}\text { Kronging } \\
\text { Bronjong }\end{array}$ & $\sqrt{ } \sqrt{ }$ & $\sqrt{\sqrt{ }}$ & $\sqrt{ } \sqrt{ }$ & $\sqrt{\sqrt{ }}$ & $\sqrt{ } \sqrt{ }$ & & & $\sqrt{ } \sqrt{ }$ & $\sqrt{ } \sqrt{ }$ & $\sqrt{\sqrt{ }}$ & $\begin{array}{l}\text { (Murri et } \\
\text { al., 2014) }\end{array}$ \\
\hline Geotekstil & $\sqrt{\sqrt{ }}$ & $\sqrt{\sqrt{ }}$ & $\sqrt{\sqrt{ }}$ & $\sqrt{\sqrt{ }}$ & & $\sqrt{ }$ & & $\sqrt{\sqrt{ }}$ & $\sqrt{\sqrt{ }}$ & $\sqrt{\sqrt{ }}$ & $\begin{array}{l}\text { (H.Setiaw } \\
\text { an, 2012) }\end{array}$ \\
\hline Geogrid & $\sqrt{\sqrt{ }}$ & $\sqrt{\sqrt{ }}$ & $\sqrt{ } \sqrt{ }$ & $\sqrt{ } \sqrt{ }$ & & $\sqrt{ }$ & & $\sqrt{\sqrt{ }}$ & $\sqrt{\sqrt{ }}$ & $\sqrt{\sqrt{ }}$ & $\begin{array}{c}\text { (Ganda \& } \\
\text { Roesyanto } \\
\text {, 2012) }\end{array}$ \\
\hline $\begin{array}{l}\text { Geoframe } \\
\text { Gerate }\end{array}$ & $\sqrt{\sqrt{ }}$ & $\sqrt{\sqrt{ }}$ & $\sqrt{\sqrt{ }}$ & $\sqrt{\sqrt{ }}$ & & $\sqrt{ }$ & & $\sqrt{\sqrt{ }}$ & $\sqrt{\sqrt{ }}$ & $\sqrt{\sqrt{ }}$ & $\begin{array}{c}\text { (Tijani, } \\
2015)\end{array}$ \\
\hline $\begin{array}{l}\text { Konven- } \\
\text { sional }\end{array}$ & $\sqrt{\sqrt{ }}$ & $\sqrt{\sqrt{ }}$ & $\sqrt{\sqrt{ }}$ & $\sqrt{\sqrt{ }}$ & & $\sqrt{\sqrt{ }}$ & & $\sqrt{\sqrt{ }}$ & $\sqrt{\sqrt{ }}$ & $\sqrt{\sqrt{ }}$ & $\begin{array}{c}\text { (Fitridawati } \\
\text { Soehardi et } \\
\text { al., 2018) }\end{array}$ \\
\hline $\begin{array}{l}\text { Dinding } \\
\text { Segmental }\end{array}$ & $\sqrt{ } \sqrt{ }$ & $\sqrt{ } \sqrt{ }$ & $\sqrt{ } \sqrt{ }$ & $\sqrt{ } \sqrt{ }$ & & $\sqrt{ } \sqrt{ }$ & & $\sqrt{ } \sqrt{ }$ & $\sqrt{ } \sqrt{ }$ & $\sqrt{ } \sqrt{ }$ & $\begin{array}{l}\text { (Mazni et } \\
\text { al., 2018) }\end{array}$ \\
\hline $\begin{array}{l}\text { Diaphragm } \\
\text { Wall,Secant } \\
\text { Pile dan } \\
\text { Soldier Pile }\end{array}$ & $\sqrt{\sqrt{ }}$ & $\sqrt{\sqrt{ }}$ & $\sqrt{\sqrt{ }}$ & $\sqrt{\sqrt{ }}$ & & $\sqrt{\sqrt{ }}$ & & $\sqrt{\sqrt{ }}$ & $\sqrt{\sqrt{ }}$ & $\sqrt{\sqrt{ }}$ & $\begin{array}{c}\text { (Fadhillah } \\
\text { et al., } \\
\text { 2013) }\end{array}$ \\
\hline $\begin{array}{l}\text { Kombinasi } \\
\text { Geotekstil , } \\
\text { angkur Soil } \\
\text { Nailing }\end{array}$ & $\sqrt{\sqrt{ }}$ & $\sqrt{\sqrt{ }}$ & $\sqrt{\sqrt{ }}$ & $\sqrt{\sqrt{ }}$ & & $\sqrt{\sqrt{ }}$ & & $\sqrt{\sqrt{ }}$ & $\sqrt{\sqrt{ }}$ & $\sqrt{\sqrt{ }}$ & $\begin{array}{l}\text { (Riogilang } \\
\text {, 2014) }\end{array}$ \\
\hline
\end{tabular}

Note: $\sqrt{ }$ adalah level dari penilaian 
Bronjong sering dipergunakan karena dapat menahan gerakan baik vertikal maupun horizontal, sifat bronjong dapat meloloskan air sehingga air dapat terus lewat sementara pergerakan tanah dapat ditahan oleh bronjong. Bronjong juga dapat menahan longsoran, mencegah erosi tanah, dan bronjong dalam keadaan runtuh masih dapat dimanfaatkan lagi serta dapat meningkatkan stabilitas lereng secara efektif.(Murri et al., 2014). Namun dalam Kondisi terendam banyak ditemukan kawat pembungkus bangunan bronjong yang patah dan lepas akibat kawat besi mengalami korosi sehingga berkarat dan akhirnya patah, hal ini disebabkan kondisi bronjong yang terendam air sungai dan mengalami pasang surut.(Fitridawati Soehardi \& Dinata, 2018)

Geotekstil merupakan produk berbahan Geosynthetics (Geosintetik) yang tembus air, dan berfungsi sebagai separator, filter, proteksi, dan perkuatan. Bahan dasar pembuatannya adalah Polyesther atau Polyprophilene. Secara umum terbagi menjadi dua jenis : Non Woven dan Woven. Dinding penahan tanah menggunakan Geotekstile sudah lama di gunakan di Negara jepang. penggunaan geotektil sebagai metode perkuatan lerengberfungsi untuk memperkuat dan menstabilk an tanah yang mempunyai daya dukung sangat buruk di daerah lereng maupun di daerah datar. Faktor yang membuat teknik geotextil ini lebih diinginkan dari pada metode lain yaitu lebih mudah di gunakan(Salle \& Hendra Riogilang, 2015). Disain perkuatan menggunakan modifikasi geogrid dan steel facing dan anchor pin telah dipilih untuk lereng yang curam untuk mencapai kemampuan maksimal dan adanya reduksi biaya. Untuk kondisi lereng yang memiliki kandungan batuan bongkah besar dipertimbangkan untuk dibuat berundak dan dibuatkan konstruksi penahan reruntuhan batuan.(Salle \& Hendra Riogilang, 2015)

Dinding penahan tanah konvensional tipe Counterfort masih banyak diminati karena mempunyai daya tahan yang kuat dan tahan namun pelaksanaan yang rumit dan biaya yang mahal masih menjadi kendala. Namun Faktor keamana stabilitas terhadap guling, stabilitas terhadap geser dan satabilitas daya dukung adalah kondisi aman(Ciptaning, Yunus, \& Saleh, 2018)

Dinding penahan segmental-tanah bertulang merupakan material komposit yang terdiri dari blok-blok beton dinding penahan segmental tanah dan tulangantulangan goesintetik. Element-elemen dinding penahan segmental pada tipe dinding penahan segmental-tanah bertulang dibuat dari beton cetak tanpa tulangan beton di dalamnya, dengan bentuk yang juga bervariasi. Dimensi dan kekuatan tulangan geosinteteik, serta berat massa tanah urug berpengaruh terhadap kestabilan dinding penahan segmental. Umumnya, tulangan geosintetik terbuat dari bahan lembaran polymeric yang mempunyai kuat tarik tinggi. Ujung depan tulangan-tulangan geosintetik ini ditindih di antara elemenelemen segmental. Panjang dari tulangan-tulangan disesuaikan berdasarkan persyarat intern dan stabilitas ekstern. Dinding penahan dianggap sebagai satu sistem komposit yang terdiri dari tumpukan elemenelemen segmental, tanah dan tulangantulangan.

Beberapa keuntungan pada penggunaan dinding penahan segmentaltanah bertulang adalah:

1. Dinding penahan segmental lebih awet karena terbuat dari blok-blok beton tak bertulang, sehingga 
harganya relatif murah dengan bentuk yang dapat bervariasi.

2. Dinding penahan segmental-tanah bertulang dalam satu kesatuan merupakan suatu satu kesatuan sistem yang fleksibel, sehingga jika penurunan tak seragam (differential settlement) terjadi maka dinding penahan tidak mengalami kerusakan secara struktural hal ini disebabkan pemasangan elemen-elemen segmental yang dipasang dengan ditumpuk-tumpuk mudah menyesuaikan bentuk bila terdapat gerakan dinding. Dinding penahan segmental tekana air tidak besar Karen kondisi dinding lolos air (Sholeh \& Yunaefi, 2016).

\section{E. KESIMPULAN}

Berdasarkan pengamatan dilapangan kelongsoran lereng Kampus Fakultas Ilmu administrasi Universitas lancing kuning adalah air hujan yang masuk kedalam pori-pori tanah sehingga mengakibatkan lunaknya tanah sehingga tanah mengalami kehilangan kapasitas dukungnya. Hal ini diperparah dengan penumpukan daun akasia yang menambah tingkat kelembaban pada tanah.Berdasarkan kondisi dilapangan maka dapat direkomendasikan penggunaan dinding Penahan tanah menggunakan bronjong, Geotekstil dan Segmental lebih efektif dan efisien.

\section{F. DAFTAR PUSTAKA}

Achmad, F. (2010). Studi Identifikasi Penyebab Longsor Di Botu Fadly Achmad Dosen Jurusan Teknik Sipil Fakultas Teknik Universitas Negeri Gorontalo.

Adi, A. D. (2016). Anyaman Bambu Sebagai Temporary Reinforced Soil Retainingwall Pada Badan Jalan Kereta Api, 1-8.
Ciptaning, K., Yunus, Y., \& Saleh, S. M. (2018). Analisis Stabilitas Lereng Dengan Kontruksi Dinding Penahan Tanah Tipe Counterfort. Jurnal Arsip Rekayasa Sipil Dan Perencanaan, 1(2), 58-68. https://doi.org/10.24815/jarsp.v1i2. 10942

Dinata, M., Fitridawati, F., \& Putri, L. D. (2019). The Study Trees Potential for Forest in Universitas Lancang Kuning Pekanbaru. EKSAKTA: Berkala Ilmiah Bidang MIPA, 20(1), 77-85. https://doi.org/10.24036/eksakta/vo 120-iss $1 / 176$

Fadhilah, L., \& Sudarno. (2017). Perencanaan dinding penahan tanah untuk perbaikan longsor di ruas jalan balerejo kalegen. Reviews in Civil Engineering, 1(1), 25-28.

Fadhillah, M. H., Mochtar, I. B., Sipil, J. T., Teknik, F., Teknologi, I., Nopember, S., ... Parameter, A. (2013). Diaphragm Wall, Secant Pile , Dan Soldier Pile Pada Pembangunan Proyek Mass Rapid Transit Jakarta, 1(1), 1-6.

Ganda, I., \& Roesyanto. (2012). GEOGRID ( Studi Kasus Jalan Medan - Berastagi , Desa Sugo. Teknik Sipil Universitas Sumatera Utara.

Gholo, K. B. M. (2014). Evaluasi Perkuatan Tebing Sungai Sukun Di Kepanjen. Universitas Tribhuwana Tunggadewi.

H.Setiawan. (2012). Perencanaan Dinding Penahan Tanah Dengan Perkuatan Geotekstil (Studi Kasus Jalan Lingkar Donggala) Design of Retaining Walls with Geotextile Reinforcement (Case Study of Donggala Ring Road). Infrastruktur. 
Hardiyatmo, H. C. (2007). Pemeliharaan Jalan Raya Perkerasan, Drainase, Longsoran. Yogyakarta: Gadjah Mada University Press.

Haris, V. T., Lubis, F., \& Winayati, W. (2018). Nilai Kohesi Dan Sudut Geser Tanah Pada Akses Gerbang Selatan Universitas Lancang Kuning. SIKLUS: Jurnal Teknik Sipil, 4(2), 123-130. https://doi.org/10.31849/siklus.v4i 2.1143

Karnawati, D. (2005). Geologi Umum dan Teknik. Yogyakarta: Program Studi S2 Teknik Sipil UGM.

Lestari, E. (2017). Sistem Drainase Aliran Bawah Tanah Untuk Daerah Rawan Longsor (Studi Kasus Sub Das Sungai Cikapundung, Bandung). Forum Mekanika, 6(2), 81-87.

https://doi.org/10.33322/forummek anika.v6i2.121

Mazni, D. I., Hakam, A., Tanjung, J., Yossyafra, Febrin, \& Ismail, A. (2018). Dinding penahan tanah (pp. 56-65).

Murri, M. M., Surjandari, N. S., \& As;ad, S. (2014). Analisis stabilitas lereng dengan pemasangan bronjong (studi kasus di sungai gajah putih, surakarta). E-Journal Matriks Teknik Sipil, 2(1), 162-169.

Riogilang, H. (2014). Soil Nailing Dan Anchor Sebagai Solusi Aplikatif Penahan Tanah Untuk Potensi Longsor Di Sta 7+250 Ruas Jalan Manado-Tomohon. Jurnal Ilmiah Media Engineering, 4(2), 119-126.

Rusdiansyah. (2016). Asumsi Sistem Cerucuk Sebagai Alternatif Solusi. Prosiding Seminar Nasional Geoteknik 2016, 250-278.
Salle, K. M., \& Hendra Riogilang, O. B. A. S. (2015). Pemeriksaan Kekuatan Tanah Dengan Menggunakan Geotextil Berlapis (Studi Kasus : Ring Road)Pemeriksaan Kekuatan Tanah Dengan Menggunakan Geotextil Berlapis (Studi Kasus : Ring Road). Tekno, 13(63), 33-42.

Sholeh, M., \& Yunaefi. (2016). Penggunaan Blok Beton Segmental Sebagai Dinding Penahan Dengan Diperkuat Geosintetik. Prokons: Jurnal Teknik Sipil, 10(2), 120126.

Soehardi, Fitridawai, \& Dinata, M. (2018). Pengaruh Kecepatan Arus Terhadap Erosi Sungai Siak Dan Kerusakan Dinding Penahan Tanah. Jurnal Konferensi Teknik Sipil, 1(7), 189-196. Retrieved From

Https://Scholar.Google.Co.Id/Citat ions?User=Sglu5vwaaaaj\&Hl=En

Soehardi, Fitridawati, \& Dinata, M. (2018). Jurnal Teknik Sipil Unaya, 4(2), 40-50. Retrieved From Http://Jurnal.Abulyatama.Ac.Id/In dex.Php/Tekniksipilunaya/Article/ View/32

Soehardi, Fitridawati, Hakam, A., Thamrin, R., Doktoral, M., Sipil, T., Teknik, F., ... Andalas, U. (2018). Alternatif Penggunaan Perkuatan Geoframe Untuk Stabilitas Lereng, (November), 111.

Tijani, M. R. (2015). Metode Perkuatan Lerengmenggunakan Geoframe Dan Geosintetikpada Proyek Green Valleygunung Guntur Balikpapan. Sekolah Vokasi Universitas Gadjah Mada Yogyakarta.

Zainuri, Yanti, G., \& Megasari, S. W. (2016). Analisis karakteristik tanah dan stabilitas lereng fakultas 
Soehardi, F., Dinata,M., Putri, L.D., / Studi Identifikasi Kerusakan / pp. 114 -124

ekonomi universitas lancang kuning. Jurnal Teknik Sipil Siklus, 2(2), 125-134.

\section{(c) (1) Sipil All rights reserved. This is an open access article distributed under the terms of the CC BY License (http://creativecommons.org/licenses/by/4.0/)}

